\title{
Roles of the kidney in the formation, remodeling and repair of bone
}

\author{
Kai Wei ${ }^{1,2} \cdot{\text { Zhiwei } \text { Yin }^{1} \cdot \text { Yuansheng Xie }}^{1}$
}

Received: 28 December 2015/Accepted: 5 February 2016/Published online: 4 March 2016

(c) The Author(s) 2016. This article is published with open access at Springerlink.com

\begin{abstract}
The relationship between the kidney and bone is highly complex, and the kidney plays an important role in the regulation of bone development and metabolism. The kidney is the major organ involved in the regulation of calcium and phosphate homeostasis, which is essential for bone mineralization and development. Many substances synthesized by the kidney, such as $1,25(\mathrm{OH})_{2} \mathrm{D}_{3}$, Klotho, bone morphogenetic protein-7, and erythropoietin, are involved in different stages of bone formation, remodeling and repair. In addition, some cytokines which can be affected by the kidney, such as osteoprotegerin, sclerostin, fibroblast growth factor -23 and parathyroid hormone, also play important roles in bone metabolism. In this paper, we summarize the possible effects of these kidney-related cytokines on bone and their possible mechanisms. Most of these cytokines can interact with one another, constituting an intricate network between the kidney and bone. Therefore, kidney diseases should be considered among patients presenting with osteodystrophy and disturbances in bone and mineral metabolism, and treatment for renal dysfunction may accelerate their recovery.
\end{abstract}

Keywords Kidney $\cdot$ Bone $\cdot 1,25(\mathrm{OH})_{2} \mathrm{D}_{3} \cdot$ Klotho $\cdot$ Bone morphogenetic protein-7 $\cdot$ Erythropoietin

Yuansheng Xie

xieyuansn@hotmail.com

1 Department of Nephrology, Chinese PLA General Hospital, Chinese PLA Institute of Nephrology, State Key Laboratory of Kidney Diseases, National Clinical Research Center for Kidney Diseases, 28 Fuxing Road, Beijing 100853, People's Republic of China

2 Medical College, NanKai University, Tianjin 300071, People's Republic of China

\section{Introduction}

The relationship between the kidney and bone is a field that has been explored for a very long time. Over 2000 years ago, the earliest Chinese medical literature 'Huangdi Neijing' systematically expounded the theory "shen zhu gu" (kidney controls bone) from the perspective of traditional Chinese medicine. In 1943, two Chinese physicians introduced the term "renal osteodystrophy" to describe the cases of osseous disorder associated with renal insufficiency [1]. All bone abnormalities related to chronic kidney disease (CKD) ultimately lead to an increased risk of fracture, which has become an important cause of morbidity and decreased quality of life [2]. Hence, normal function of kidney is important for bone health, and to illustrate the potential relationships between kidney and bone becomes an urgent issue. In this review, we recapitulate the possible links between the kidney and bone with a main focus on the role of the kidney.

\section{The kidney is the major organ for homeostasis of calcium and phosphate}

The homeostasis of calcium and phosphate is complicated. In calcium and phosphate balance, more than $97 \%$ of calcium and $80 \%$ of phosphate filtered in the kidney are reabsorbed at different segments of the tubules, and their homeostasis can be severely affected in kidney diseases [3, 4]. The majority of the calcium and phosphate in our body resides in bone, and these two elements are critical for the normal structure and function of bone [5]. Calcium and phosphate are the main components of bone minerals. Beyond that, they also have some biological effects. Calcium can directly stimulate osteoblast formation while inhibiting osteoclast 
formation via calcium-sensitive receptor (CaSR) dependent or independent pathways [6, 7]. However, phosphate can directly promote osteoclast apoptosis and inhibit its differentiation by affecting receptor activator of nuclear factor- $\kappa \mathrm{B}$ (RANK)-RANK ligand (RANKL) signaling and osteoprotegerin (OPG) [8, 9]. This indicates that the kidney may affect the structure and function of bone by regulating the homeostasis of calcium and phosphate.

\section{The kidney regulates bone health by generating activated vitamin D}

$1,25(\mathrm{OH})_{2} \mathrm{D}_{3}$ is the activated pattern of vitamin $\mathrm{D}$, and the circulating $1,25(\mathrm{OH})_{2} \mathrm{D}_{3}$ (calcitriol) is mainly produced in the proximal renal tubules under the hydroxylation of $1 \alpha$ hydroxylase $[1 \alpha(\mathrm{OH})$ ase], which is encoded by cyp $27 \mathrm{bl}$ [10]. It regulates the homeostasis of calcium and phosphate, and bone development and repair by binding vitamin $\mathrm{D}$ receptor (VDR) located in the intestine, kidney and bone.

$1,25(\mathrm{OH})_{2} \mathrm{D}_{3}$ promotes calcium and phosphate uptake and reabsorption by increasing the expression of their transport proteins in enterocytes and renal tubule cells [3, 11]. Apart from that, direct effects on bone are also observed. Chondrocyte-specific $v d r$ inactivation in mice shows that $1,25(\mathrm{OH})_{2} \mathrm{D}_{3}$ controls vascular invasion and osteoclast formation by increasing vascular endothelial growth factor (VEGF) and RANKL [12]. For osteoblast, $1,25(\mathrm{OH})_{2} \mathrm{D}_{3}$ affects the synthesis of collagen $\mathrm{I}$ and expression of alkaline phosphatase (ALP), osteocalcin and osteopontin [13, 14], stimulates bone matrix mineralization via accelerating the production of mature micro vesicles and modulates the bone microenvironment by regulating the osteoblastic niche $[15,16]$. For osteoclast, $1,25(\mathrm{OH})_{2} \mathrm{D}_{3}$ plays bidirectional roles. On the one hand, it stimulates osteoclastogenesis by increasing the expression of RANKL on chondrocyte and osteoclast $[12,17]$. On the other hand, in osteoclast precursors, $1,25(\mathrm{OH})_{2} \mathrm{D}_{3}$ directly suppresses the expression of RANK via down-regulation of c-Fms, inhibits key regulators of osteoclast formation, c-Fos and NFATc1, and increases its inhibitor, CCAAT enhancer-binding proteins [18-21]. Therefore the comprehensive effects of $1,25(\mathrm{OH})_{2} \mathrm{D}_{3}$ on osteoclast, osteoclastogenesis and bone resorption need to be further investigated.

In addition, $1,25(\mathrm{OH})_{2} \mathrm{D}_{3}$ can stimulate fibroblast growth factor (FGF)-23 secretion in osteocytes via binding vitamin D response element (VDRE) [22]. Reversely, FGF23 suppresses $1,25(\mathrm{OH})_{2} \mathrm{D}_{3}$ levels via its effects on the kidney to stimulate CYP24A1-mediated degradation and suppress $1 \alpha(\mathrm{OH})$ ase-mediated production [23]. The negative feedback loop between them plays an important role in the crosstalk between the kidney and bone (Fig. 1).

\section{The kidney maintains bone formation and remodeling by producing Klotho}

Klotho is identified as an "aging suppressor" protein, which is primarily expressed in renal distal convoluted tubules [24]. It can be divided into membrane-binding and soluble forms. Membrane-binding Klotho forms a complex with FGF receptors (FGFRs) and functions as an essential co-receptor for FGF-23 [25]. The Klotho/FGFR/FGF-23 complex, except for its effect on $1,25(\mathrm{OH})_{2} \mathrm{D}_{3}$ mentioned above, can suppress sodium-phosphate ( $\mathrm{NaPi}$ ) co-transport activity in kidney and reduce phosphate reabsorption [26]. Furthermore, as for proximal tubule epithelial cells (PTEC), exposure to both FGF-23 and Klotho initiates Ras and phosphatidylinositol 3-kinase (PI3K) signaling pathways manifested by up-regulation in phosphorylation of ERK1/2, p38, JNK, AKT, IkB and GSK-3 $\beta$. Combined application of FGF-23 and Klotho rescues high $1,25(\mathrm{OH})_{2} \mathrm{D}_{3}$-induced apoptosis of PTEC, while PI3K inhibitor prevents the effect of FGF-23 and Klotho [27]. Therefore, both Ras and PI3K signaling pathways may be involved in the crosstalk between the kidney and bone.

Different from membrane-binding Klotho, soluble Klotho can be released into the circulation and act on remote organs in FGF-23 dependent and independent ways. Soluble Klotho interacts with the FGFRs in osteoblast and facilitates FGF-23 induced proliferation and inhibition of mineralization [28]. In addition, it can exert phosphaturic effects independently. In normal and $F g f 23^{-/-}$mice, soluble Klotho is able to inactivate $\mathrm{NaPi}$-IIb in the intestine and NaPi-IIa in the proximal renal tubules to reduce phosphate absorption and reabsorption [24]. Furthermore, it can also activate calcium channels transient receptor potential vanilloid receptor (TRPV) 5/6 and conserve serum calcium and reduce calciuria [29, 30]. Since soluble Klotho can inhibit IGF-1, Wnt and transforming growth factor- $\beta$ (TGF- $\beta$ ) signaling pathways in aging and in certain cancers [31], whether these pathways are involved in the Klotho-induced regulation of bone formation still needs to be investigated.

In addition, direct effects of Klotho on bone formation and remodeling are also observed. Klotho deficient mice show low bone formation and bone resorption activities, which result in osteopenia [32]. Histological studies show that the expression of osteocalcin and dentinmatrix protein1 (DMP-1) were weak and uneven in the tibiae matrix of the Klotho $^{-1-}$ mice, and matrix Gla protein (MGP) expressed in the cartilage cores and bone surfaces, which were different from wild type mice whose MGP mainly expressed at the junction between cartilage and bone [32]. Furthermore, the Klotho ${ }^{-1-}$ mice fail to have formed compact bone in lumbars manifested as abundant 


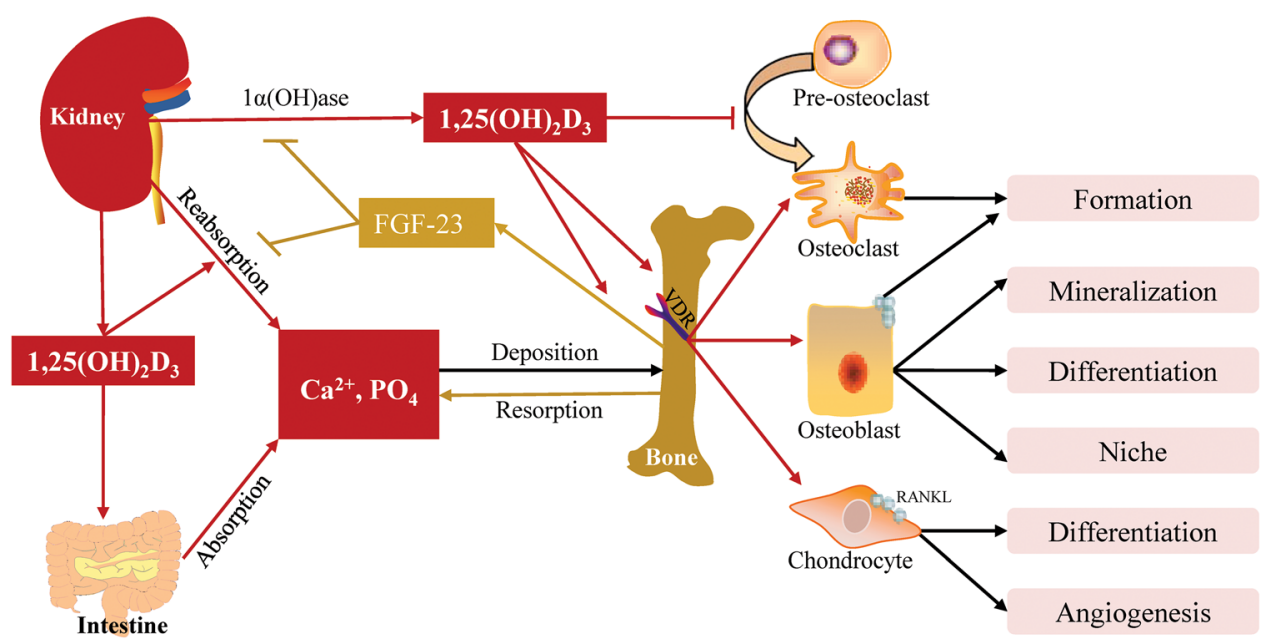

Fig. 1 Actions of $1,25(\mathrm{OH})_{2} \mathrm{D}_{3}$ on calcium and phosphate homeostasis and bone development. $1,25(\mathrm{OH})_{2} \mathrm{D}_{3}$ synthesized by the kidney promotes the absorption and reabsorption of calcium and phosphate in the intestine and kidney, stimulates FGF-23 production in bone, which inhibits $1,25(\mathrm{OH})_{2} \mathrm{D}_{3}$ synthesis and phosphate reabsorption in kidney. $1,25(\mathrm{OH})_{2} \mathrm{D}_{3}$ exerts osteogenic effects on

osteocytes, pyknotic osteocytes and random empty lacunae [33]. Although osteoblasts from these mice proliferate normally in vitro, their ability to produce ALP and to mineralize extracellular matrix is reduced. Moreover, the low bone resorption activities related to the impaired osteoclastogenesis appears to be associated with up-regulation of OPG synthesis, which can suppress osteoclast differentiation [34, 35] (Fig. 2). However, Klotho overexpression can also result in reduced bone mineral content, expanded growth palates and fracture [36]. Therefore, kidney derived Klotho acts on bone either independently or in cooperation with bone derived FGF-23, and both the pathological increase and decrease of Klotho can cause disturbed bone development and metabolism; hence, a desired range of circulating Klotho is critical for bone health.

\section{The kidney modulates bone development by producing bone morphogenetic protein-7}

Bone morphogenetic protein-7 (BMP-7), a member of the TGF- $\beta$ superfamily, was originally isolated from demineralized bone based on its ability to induce new bone formation. The kidney has been identified as the major site for BMP-7 synthesis during embryonal and postnatal development [37]. As a determinant of the embryogenesis of bone, the effects of BMP-7 on bone have been widely investigated in different types of animal models. It has been demonstrated that BMP-7 can induce bone formation, enhance incomplete fracture and bone defects, even osteoblasts and chondrocytes and inhibits osteoclast differentiation while promoting its maturation by up-regulating RANKL expression in osteoblasts. $\rightarrow$ : produce or promote; $\longrightarrow$ : inhibit, $1 \alpha-(\mathrm{OH})$ ase: $1 \alpha-$ hydroxylase, $\mathrm{Ca}^{2+}$ : calcium, FGF: fibroblast growth factor, $\mathrm{PO}_{4}$ : phosphate, RANKL: receptor activator of nuclear factor NF- $\kappa \beta$ ligand, VDR: vitamin D receptor

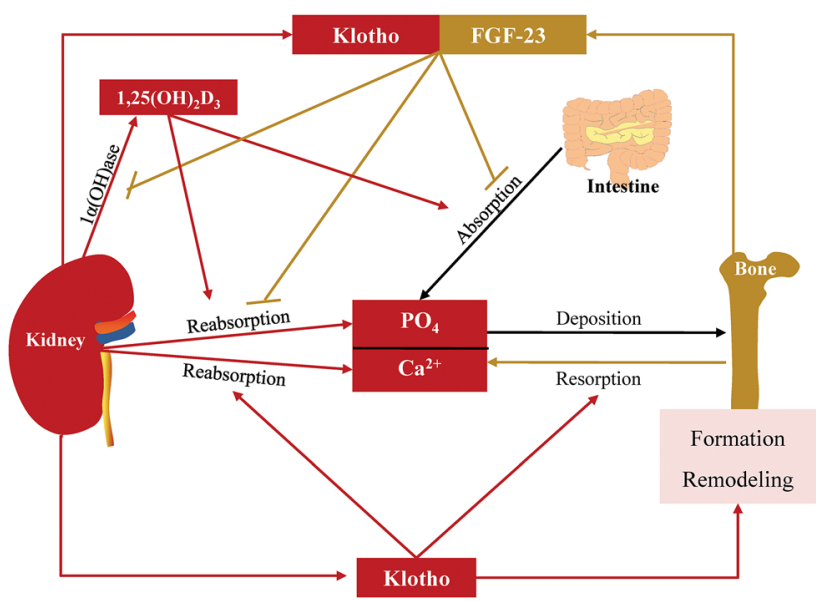

Fig. 2 Actions of Klotho on calcium and phosphate homeostasis and bone. The complex of Klotho and FGF-23 inhibits $1,25(\mathrm{OH})_{2} \mathrm{D}_{3}$ synthesis and phosphate reabsorption in the kidney. Soluble Klotho stimulates calcium reabsorption and resorption in the kidney and bone, inhibits calcium and phosphate absorption in intestine and regulates bone formation and remodeling. $\rightarrow$ : produce or promote, $\longrightarrow$ : inhibit, $1 \alpha(\mathrm{OH})$ ase: $1 \alpha$-hydroxylase, $\mathrm{Ca}^{2+}$ : calcium, FGF: fibroblast growth factor, $\mathrm{PO}_{4}$ : phosphate

ameliorate osteonecrosis, osteoarthritis and intervertebral disc degeneration [38-40]. Mechanisms underlying the beneficial effects of BMP-7 on bone are sophisticated. For chondrocytes, BMP-7 can promote chondrocyte differentiation from bone marrow mesenchymal stem cells (BMMSCs) and exert anabolic effects by stimulating synthesis of extracellular matrix proteins [41]. In addition, BMP-7 can exert anti-catabolic effects on chondrocytes by blocking metalloproteinase (MMP)-1, MMP-13 and a 
disintegrin and metalloproteinase with thrombospondin motifs (ADAMTMS) that destroy the extracellular matrix and cartilage [40, 42]. In some cases, BMP-7 can also promote chondrocyte maturation manifested by hypertrophy and increased expression of ALP [43]. For osteoblasts, BMP-7 is capable of inducing its differentiation from BMMSCs by expressing osteoblast differentiation markers, such as ALP and Runx2, stimulating the proliferation of mature osteoblasts, inducing collagen synthesis and enhancing its activity by expressing osteocalcin [41, 44, 45]. The potential mechanisms involved in the above processes are far more complicated. As members of the TGF- $\beta$ superfamily, BMP-7 can activate canonical signaling including Smad1/4/5/8 and non-canonical TAK1/ MKK/p38 signaling. In addition, the interplay between BMPs and Notch, Hh, FGF as well as Wnt signaling also plays a very important role in osteoblast and bone [46]. However, whether those signaling pathways are involved in the BMP-7 induced bone development still needs to be investigated.

There is a relatively low level of BMP-7 production in bone, and it seems not to be required for skeletal homeostasis because conditional deletion of BMP-7 from the limb skeleton has no effect on postnatal limb growth, articular cartilage formation, maintenance of bone mass, or fracture healing [47]. The results above suggest that extra-skeletal derived BMP-7 may be more important in bone formation and growth. The kidney is the major site of BMP-7 synthesis, and BMP-7 produced in the kidney is constantly released into the circulation, functioning at distant sites in a hormone-like manner [48]. Furthermore, in rat models of osteodystrophy due to renal mass ablation, administration of recombinant BMP-7 can successfully inhibit the bone disorder [49] (Fig. 3). All of the above indicate that BMP-7, which is required for normal bone development and metabolism, originates from the kidney.

\section{The kidney promotes bone development and fracture healing by synthesizing erythropoietin}

Erythropoietin (EPO) is a $30.4 \mathrm{kD}$ glycoprotein and class I cytokine that is characterized by its role in the regulation of red blood cell production in bone marrow due to its expression of EPO receptor (EPO-R) [50]. Approximately $90 \%$ of systemic EPO in adults is produced by peritubular interstitial fibroblasts in the renal cortex and outer medulla of the kidney [51]. In recent years, with the identification of non-hematopoietic EPO-R and CD131, the non-hematopoietic effects of EPO have begun to be investigated.

Recent studies indicate that EPO plays an important role in bone formation, fracture healing and intervertebral disc degeneration. In fracture models of mice, it has been found that the terminally differentiated chondrocytes within the callus expressed EPO-R and that administration of recombined EPO is capable of stimulating endochondral ossification, cell proliferation and VEGF-mediated angiogenesis [52]. A rabbit model of autograft posterolateral spinal fusion also shows that systemic EPO administration can increase bone volume and neovascularization [53]. First, EPO can increase BMP2 expression by hematopoietic stem cells (HSCs) through the JAK2/Stat3 signaling pathway. Then, EPO can induce osteoblasts differentiation from BMMSCs in vitro and bone formation in vivo either directly or indirectly by the expression of BMP-2 by HSCs [54]. In addition, EPO can increase osteoclast numbers, but its effects on osteoclast activity still need to be investigated [55]. Further investigations demonstrate that the osteogenic and osteoclastogenesis effects of EPO can be mediated by three intracellular signaling pathways: mammalian target of rapamycin (mTOR), JAK2 and PI3K [56] (Fig. 4). Given that EPO is a renal hormone, the kidney likely plays an important role in bone formation and fracture healing via EPO.
Fig. 3 Actions of BMP-7 on bone. Kidney produces BMP-7. BMP-7 stimulates chondrocyte and osteoblast differentiation from MSC; it also induces their osteogenesis. $\rightarrow$ : produce or promote, $\longrightarrow$ : inhibit, BMP: bone morphogenetic protein, MSC: mesenchymal stem cell

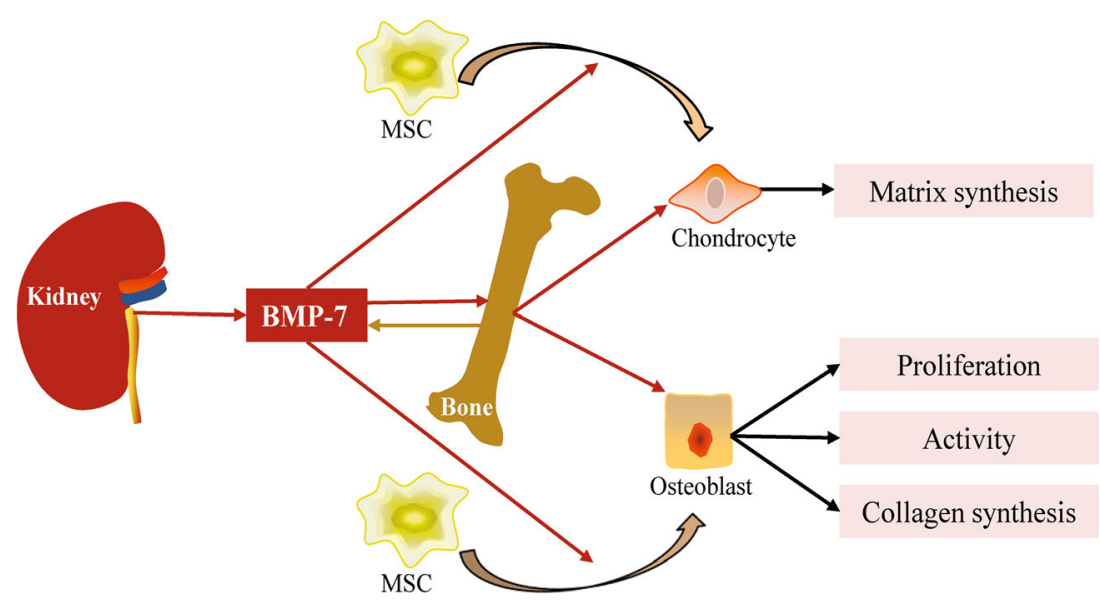




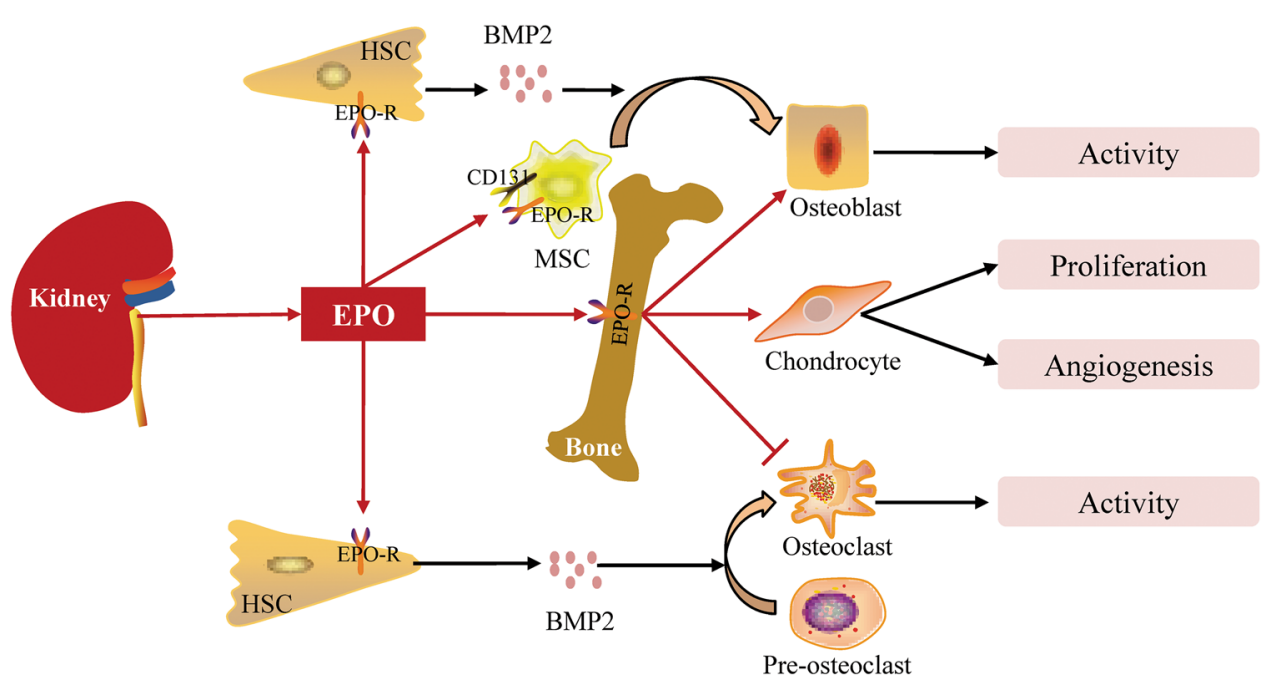

Fig. 4 Actions of EPO on bone. EPO produced by the kidney promotes osteoblast activity, stimulates chondrocyte proliferation and angiogenesis and decreases osteoclast activity by binding EPO-R. EPO stimulates osteoblast and osteoclast differentiation from their precursors by up-regulating BMP2 expression by HSC and stimulates

\section{Other factors that are involved in the regulation of bone remodeling}

Osteoprotegerin, secreted by osteoblast lineage cells, belongs to the tumor necrosis factor (TNF) family of receptors [57]. Known as a decoy receptor for the proosteoclastic cytokine RANKL, OPG can inhibit osteoclast differentiation and activation. Clinical studies indicate that the levels of OPG are increased in patients with CKD stages I through $\mathrm{V}$ and that serum levels of OPG correlate with serum creatinine levels and have a reciprocal relationship to creatinine clearance over a 24-h period [58]. Furthermore, OPG levels drop to laboratory norms after renal transplantation in parallel with renal function restoration [59]. Thus, the kidney is recognized as the major site for clearance of OPG.

Sclerostin, another bone formation regulator, is secreted by osteocytes. As an antagonist for BMPs and Wnt signaling, sclerostin can modulate the activity of osteoblasts by reducing ALP activity, synthesis of type I collagen and mineralization [60, 61]. In addition, sclerostin can also promote osteoblast apoptosis in vitro [62]. Recent studies show that serum sclerostin levels are increased in patients with CKD and are negatively correlated with estimated glomerular filtration rate (eGFR) following correction for age and gender. Moreover, the elevated serum sclerostin levels reduce rapidly in parallel with the improvement of renal function, which suggests that the kidney probably participates in sclerostin clearance [63, 64]. Therefore, the kidney can also regulate bone formation by clearing some bone regulators. osteoblast differentiation from MSC by binding EPO-R or CD131. $\rightarrow$ : produce or promote, $\longrightarrow$ : inhibit, BMP: bone morphogenetic proteins, EPO: erythropoietin, EPO-R: erythropoietin receptor, HSC: hematopoietic stem cell, MSC: mesenchymal stem cell

In addition, parathyroid hormone (PTH) and FGF-23 are key regulators in mediating bone and mineral abnormalities caused by CKD. Both PTH and FGF-23 begin to increase in the early stage of CKD, when the eGFR drops below $60 \mathrm{ml} / \mathrm{min}$ per $1.73 \mathrm{~m}^{2}$ [65]. Early control PTH and FGF23 can improve bone and mineral disturbances in CKD effectively $[66,67]$. PTH, on the one hand, can increase the number and activity of osteoclasts by regulating the expression of RANKL and OPG [68]; on the other hand, it can suppress chondrocyte and osteoblast differentiation manifested as reduced mineralization, and decreased expression of Runx2, ALP, procollagen I and osteocalcin via cAMP/PKA and $\mathrm{Ca}^{2+} / \mathrm{PKC}$ signaling pathways [6971]. Apart from these effects, PTH can interact with mediators between the kidney and bone, such as $1,25(\mathrm{OH})_{2} \mathrm{D}_{3}, \mathrm{FGF}-23$ and calcium. The decline of renal function results in the deficiency of $1,25(\mathrm{OH})_{2} \mathrm{D}_{3}$ and subsequent decrease of serum calcium, which increase the synthesis and secretion of PTH and even the hyperplasia of parathyroid gland through VDR and CaSR/IP3 mediated signaling pathways, respectively [7, 72]. The PTH can inversely increase serum calcium by promoting its reabsorption by the kidney and release from bone; it can also increase $1,25(\mathrm{OH})_{2} \mathrm{D}_{3}$ levels by stimulating its production and inhibiting its degeneration in the kidney [73, 74]. Furthermore, elevated PTH can increase FGF-23 expression in bone either by activation of PKA and Wnt signaling pathways in osteoblasts or by promoting $1,25(\mathrm{OH})_{2} \mathrm{D}_{3}$ production $[22,75]$. Meanwhile, the parathyroid gland is one of the target organs of FGF-23 and it can inhibit PTH synthesis either by cooperating with Klotho or via mitogen- 


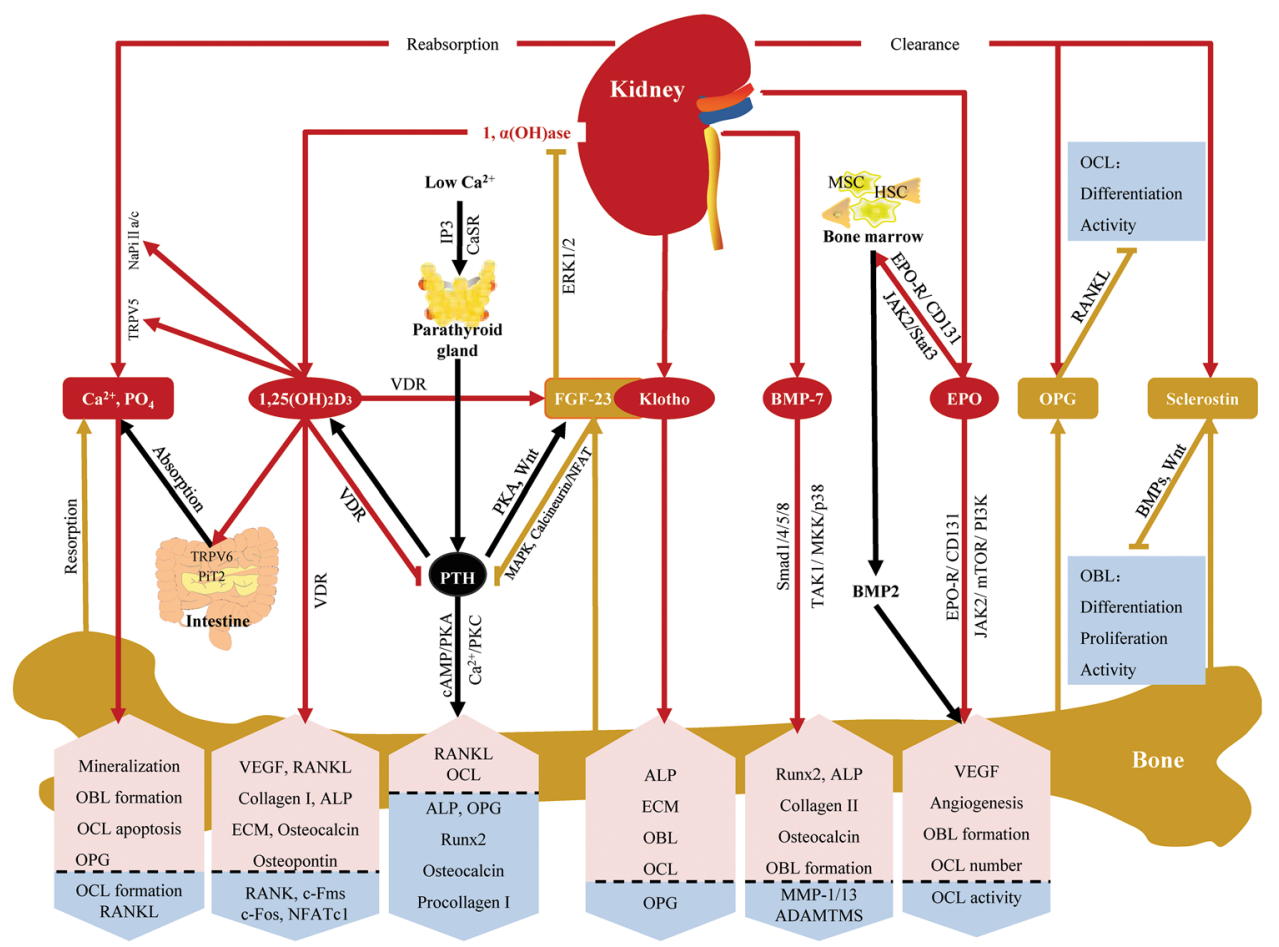

Fig. 5 The kidney affects bone development, remodeling and repair by regulating calcium and phosphate homeostasis, producing cytokines and clearing bone regulators. (1) The kidney reabsorbs calcium and phosphate via TRPV6 and NaPi IIa/c. Calcium and phosphate are not only components of bone but also exert direct effects on bone cells via CaSR mediated signaling pathways. (2) The kidney synthesizes $1,25(\mathrm{OH})_{2} \mathrm{D}_{3}$, which can increase calcium and phosphate absorption and reabsorption by stabilizing their transporters. It can also exert direct effects on bone via VDR mediated signaling pathways and increase FGF-23 production in bone. (3) The kidney produces Klotho, which functions as a collaborator with bone-derived FGF-23 to decrease $1,25(\mathrm{OH})_{2} \mathrm{D}_{3}$ or exerts direct effects on bone independently. (4) The kidney produces BMP-7, which can exert direct effects on bone by activating Smad1/4/5/8 or TAK1/MKK/p38 signaling pathways. (5) The kidney synthesizes EPO, which has both direct effects on bone by activating JAK2, mTOR and PI3K signaling pathways and indirect effects through bone marrow. (6) OPG and sclerostin are bone-derived bone regulators. They are mainly cleared in the kidney. (7) PTH mediates the crosstalk between the kidney and

activated protein kinases (MAPK) and calcineurin-mediated pathways independently [76, 77]. Therefore, there are several negative feedback loops between these factors, and their interactions play a very important role in the crosstalk between the kidney and bone.

\section{Conclusion}

The kidney and bone are tightly coupled from early embryonic development, and the relationship between them is far more complex. The kidney affects bone development, remodeling and repair by regulating calcium bone. There are several feedback loops between PTH and serum calcium, 1,25(OH) ${ }_{2} \mathrm{D}_{3}$ and FGF-23. $\rightarrow$ : produce or promote, $\longrightarrow$ : inhibit, $\longrightarrow$ (red arrow) represents the effects of kidney, $\longrightarrow$ (yellow arrow) represents the effects of bone, $\longrightarrow$ (black arrow) represents the effects of others,

(pink box with up arrow) represents up-regulation or promotion, (blue box with down arrow) represents down-regulation or inhibition, $1 \alpha(\mathrm{OH})$ ase: $1 \alpha$ hydroxylase, ADAMTMS: a disintegrin and metalloproteinase with thrombospondin motifs, ALP: alkaline phosphatase, BMP: bone morphogenetic protein, $\mathrm{Ca}^{2+}$ : calcium, CaSR: calcium-sensitive receptor, ECM: extracellular matrix, FGF: fibroblast growth factor, HSC: hematopoietic stem cell, MMP: metalloproteinase, MSC: mesenchymal stem cell, OBL: osteoblast, OCL: osteoclast, OPG: osteoprotegerin, $\mathrm{PO}_{4}$ : phosphate, $\mathrm{PTH}$ : parathyroid hormone, RANKL: receptor activator of nuclear factor NF- $\kappa \beta$ ligand, Runx2: runt-related gene 2, VDR: vitamin D receptor, VEGF: vascular endothelial growth factor

and phosphate homeostasis, producing cytokines and clearing bone regulators (Fig. 5). As all of these actions have pleiotropic effects not only on bone but also on other tissues or organs, to fully understand their diverse impacts is difficult. However,it at least gives us some hints that kidney diseases should be taken into consideration when patients present with osteodystrophy and disturbances in bone and mineral metabolism. For some of these patients, treatment for renal dysfunction may accelerate their recovery. Finally, we hope that new discoveries of the roles played by renal cytokines in bone and an increased awareness of the underlying pathophysiologic mechanisms will pave the way for more individualized therapies. 
Acknowledgments This work was supported by a Grant (81473531) from the National Natural Science Foundation of China, a Grant (2011CB944004) from the National Basic Research Program of China and a Grant (7152138) from the Beijing Natural Science Foundation.

\section{Compliance with ethical standards}

Conflict of interest The authors declare that they have no conflict of interest.

Ethical approval This article does not contain any studies with human participants or animals performed by any of the authors.

Open Access This article is distributed under the terms of the Creative Commons Attribution 4.0 International License (http://crea tivecommons.org/licenses/by/4.0/), which permits unrestricted use, distribution, and reproduction in any medium, provided you give appropriate credit to the original author(s) and the source, provide a link to the Creative Commons license, and indicate if changes were made.

\section{References}

1. Liu S, Chu H (1943) Studies of calcium and phosphorus metabolism with special reference to pathogenesis and effects of dihydrotachysterol (AT 10) and iron. Medicine 22(2):103-162

2. Moe S, Drüeke T, Cunningham J, Goodman W, Martin K, Olgaard K, Ott S, Sprague S, Lameire N, Eknoyan G (2006) Definition, evaluation, and classification of renal osteodystrophy: a position statement from kidney disease: improving global outcomes (KDIGO). Kidney Int 69(11):1945-1953. doi:10.1038/sj. ki.5000414

3. Hoenderop JG, Nilius B, Bindels RJ (2005) Calcium absorption across epithelia. Physiol Rev 85(1):373-422. doi:10.1152/phys rev.00003.2004

4. Murer H, Biber J (2010) Phosphate transport in the kidney. J Nephrol 23(Suppl 16):S145-S151

5. Barrère $\mathrm{F}$, van Blitterswijk $\mathrm{CA}$, de Groot $\mathrm{K}$ (2006) Bone regeneration: molecular and cellular interactions with calcium phosphate ceramics. Int J Nanomed 1(3):317

6. Dvorak MM, Siddiqua A, Ward DT, Carter DH, Dallas SL, Nemeth EF, Riccardi D (2004) Physiological changes in extracellular calcium concentration directly control osteoblast function in the absence of calciotropic hormones. Proc Natl Acad Sci USA 101(14):5140-5145

7. Brown EM, MacLeod RJ (2001) Extracellular calcium sensing and extracellular calcium signaling. Physiol Rev 81(1):239-297

8. Kanatani M, Sugimoto T, Kano J, Kanzawa M, Chihara K (2003) Effect of high phosphate concentration on osteoclast differentiation as well as bone-resorbing activity. J Cell Physiol 196(1):180-189. doi:10.1002/jcp. 10270

9. Mozar A, Haren N, Chasseraud M, Louvet L, Maziere C, Wattel A, Mentaverri R, Morliere P, Kamel S, Brazier M, Maziere JC, Massy ZA (2008) High extracellular inorganic phosphate concentration inhibits RANK-RANKL signaling in osteoclast-like cells. J Cell Physiol 215(1):47-54. doi:10.1002/jcp.21283

10. Anderson P, O'Loughlin P, May B, Morris H (2003) Quantification of mRNA for the vitamin D metabolizing enzymes CYP27B1 and CYP24 and vitamin D receptor in kidney using real-time reverse transcriptase-polymerase chain reaction. J Mol Endocrinol 31(1):123-132

11. Nemere I, Garbi N, Hammerling G, Hintze KJ (2012) Role of the $1,25 \mathrm{D} 3$-MARRS receptor in the $1,25(\mathrm{OH}) 2 \mathrm{D} 3$-stimulated uptake of calcium and phosphate in intestinal cells. Steroids 77(10):897-902. doi:10.1016/j.steroids.2012.04.002

12. Masuyama R, Stockmans I, Torrekens S, Van Looveren R, Maes C, Carmeliet P, Bouillon R, Carmeliet G (2006) Vitamin D receptor in chondrocytes promotes osteoclastogenesis and regulates FGF23 production in osteoblasts. J Clin Invest 116(12):3150-3159

13. Slominski AT, van der Meijden K, Lips P, van Driel M, Heijboer AC, Schulten EAJM, Heijer Md, Bravenboer N (2014) Primary human osteoblasts in response to 25-hydroxyvitamin D3, 1,25dihydroxyvitamin D3 and 24R,25-dihydroxyvitamin D3. PLoS One 9(10):e110283. doi:10.1371/journal.pone.0110283

14. Pols H, van Leeuwen $\mathbf{J}$ (2004) Osteoblast differentiation and control by vitamin D and vitamin D metabolites. Curr Pharm Des 10(21):2535-2555

15. Woeckel VJ, Alves RDAM, Swagemakers SMA, Eijken M, Chiba H, van der Eerden BCJ, van Leeuwen JPTM (2010) 1 1 ,25$(\mathrm{OH}) 2 \mathrm{D} 3$ acts in the early phase of osteoblast differentiation to enhance mineralization via accelerated production of mature matrix vesicles. J Cell Physiol 225(2):593-600. doi:10.1002/jcp. 22244

16. Lieben L, Carmeliet G, Masuyama R (2011) Calcemic actions of vitamin D: effects on the intestine, kidney and bone. Best Prac Res Clin Endocrinol Metab 25(4):561-572. doi:10.1016/j.beem. 2011.05.008

17. Takeda S, Yoshizawa T, Nagai Y, Yamato H, Fukumoto S, Sekline K, Kato S, Matsumoto T, Fujita T (1999) Stimulation of osteoclast formation by 1,25-dihydroxyvitamin $\mathrm{D}$ requires its binding to vitamin $\mathrm{D}$ receptor (VDR) in osteoblastic cells: studies using VDR knockout mice. Endocrinology 140(2):10051008

18. Kim T-H, Lee B, Kwon E, Choi CH, Sung I-H, Kim Y, Sohn J, Ji JD (2013) 1,25-dihydroxyvitamin D3 inhibits directly human osteoclastogenesis by down-regulation of the c-Fms and RANK expression. Joint Bone Spine 80(3):307-314. doi:10.1016/j. jbspin.2012.09.011

19. Takasu H, Sugita A, Uchiyama Y, Katagiri N, Okazaki M, Ogata E, Ikeda K (2006) c-Fos protein as a target of anti-osteoclastogenic action of vitamin $\mathrm{D}$, and synthesis of new analogs. J Clin Invest 116(2):528-535

20. Sakai S, Takaishi H, Matsuzaki K, Kaneko H, Furukawa M, Miyauchi Y, Shiraishi A, Saito K, Tanaka A, Taniguchi T (2009) 1-Alpha, 25-dihydroxy vitamin D3 inhibits osteoclastogenesis through IFN-beta-dependent NFATc1 suppression. J Bone Miner Metab 27(6):643-652

21. Ji J, Kim T, Lee B, Jun J, Yoo D, Choi S, Lee Y, Kim Y, Sohn J, Song G (2011) 1, 25-dihydroxyvitamin D3 inhibits osteoclast differentiation from $\mathrm{CD} 14+$ osteoclast precursors of normal peripheral blood and rheumatoid arthritis synovial fluid. Ann Rheum Dis 70(Suppl 3):354

22. Liu S, Tang W, Zhou J, Stubbs JR, Luo Q, Pi M, Quarles LD (2006) Fibroblast growth factor 23 is a counter-regulatory phosphaturic hormone for vitamin D. J Am Soc Nephrol 17(5):1305-1315

23. Shimada $T$, Hasegawa $H$, Yamazaki $Y$, Muto $T$, Hino $R$, Takeuchi Y, Fujita T, Nakahara K, Fukumoto S, Yamashita T (2004) FGF-23 is a potent regulator of vitamin D metabolism and phosphate homeostasis. J Bone Miner Res 19(3):429-435. doi:10. 1359/JBMR.0301264

24. Hu MC, Shi M, Zhang J, Pastor J, Nakatani T, Lanske B, Razzaque MS, Rosenblatt KP, Baum MG, Kuro-o M, Moe OW (2010) Klotho: a novel phosphaturic substance acting as an autocrine enzyme in the renal proximal tubule. FASEB $\mathrm{J}$ 24(9):3438-3450. doi:10.1096/fj.10-154765

25. Urakawa I, Yamazaki Y, Shimada T, Iijima K, Hasegawa H, Okawa K, Fujita T, Fukumoto S, Yamashita T (2006) Klotho 
converts canonical FGF receptor into a specific receptor for FGF23. Nature 444(7120):770-774. doi:10.1038/nature05315

26. Saito H, Kusano K, Kinosaki M, Ito H, Hirata M, Segawa H, K-i Miyamoto, Fukushima N (2003) Mechanisms of signal transduction-human fibroblast growth Factor-23 Mutants suppress $\mathrm{Na}^{+}$-dependent phosphate co-transport activity and 1a, 25-dihydroxyvitamin D3 production. J Biol Chem 278(4):2206-2211

27. Medici D, Razzaque MS, Deluca S, Rector TL, Hou B, Kang K, Goetz R, Mohammadi M, Kuro OM, Olsen BR, Lanske B (2008) FGF-23-Klotho signaling stimulates proliferation and prevents vitamin D-induced apoptosis. J Cell Biol 182(3):459-465. doi:10. 1083/jcb.200803024

28. Shalhoub V, Ward SC, Sun B, Stevens J, Renshaw L, Hawkins N, Richards WG (2011) Fibroblast growth factor 23 (FGF23) and alpha-klotho stimulate osteoblastic MC3T3.E1 cell proliferation and inhibit mineralization. Calcif Tissue Int 89(2):140-150. doi:10.1007/s00223-011-9501-5

29. Lu P, Boros S, Chang Q, Bindels RJ, Hoenderop JG (2008) The $\beta$-glucuronidase klotho exclusively activates the epithelial $\mathrm{Ca}^{2+}$ channels TRPV5 and TRPV6. Nephrol Dial Transplant 23(11):3397-3402

30. Chang Q, Hoefs S, Van Der Kemp A, Topala C, Bindels R, Hoenderop J (2005) The $\beta$-glucuronidase klotho hydrolyzes and activates the TRPV5 channel. Science 310(5747):490-493

31. Doi S, Zou Y, Togao O, Pastor JV, John GB, Wang L, Shiizaki K, Gotschall R, Schiavi S, Yorioka N (2011) Klotho inhibits transforming growth factor- $\beta 1$ (TGF- $\beta 1$ ) signaling and suppresses renal fibrosis and cancer metastasis in mice. $\mathrm{J}$ Biol Chem 286(10):8655-8665

32. Sasaki Muneteru, Hasegawa Tomoka, Yamada Tamaki (2013) Altered distribution of bone matrix proteins and defective bone mineralization in klotho-deficient mice. Bone 57(1):14. doi:10. 1016/j.bone.2013.08.008

33. Suzuki H, Amizuka N, Oda K, Li M, Yoshie H, Ohshima H, Noda M, Maeda T (2005) Histological evidence of the altered distribution of osteocytes and bone matrix synthesis in klothodeficient mice. Arch Histol Cytol 68(5):371-381

34. Kawaguchi H, Manabe N, Chikuda H, Nakamura K, Kuro-o M (2000) Cellular and molecular mechanism of low-turnover osteopenia in the klotho-deficient mouse. Cell Mol Life Sci 57(5):731-737

35. Kawaguchi H, Manabe N, Miyaura C, Chikuda H, Nakamura K, Kuro-o M (1999) Independent impairment of osteoblast and osteoclast differentiation in klotho mouse exhibiting low-turnover osteopenia. J Clin Invest 104(3):229-237. doi:10.1172/jci5705

36. Smith RC, O'Bryan LM, Farrow EG, Summers LJ, Clinkenbeard EL, Roberts JL, Cass TA, Saha J, Broderick C, Ma YL (2012) Circulating $\alpha$ Klotho influences phosphate handling by controlling FGF23 production. J Clin Invest 122(12):4710-4715

37. Boon MR, van der Horst G, van der Pluijm G, Tamsma JT, Smit JWA, Rensen PCN (2011) Bone morphogenetic protein 7: a broad-spectrum growth factor with multiple target therapeutic potency. Cytokine Growth Factor Rev 22(4):221-229. doi:10. 1016/j.cytogfr.2011.08.001

38. Papanagiotou M, Malizos K, Vlychou M, Dailiana Z (2014) Autologous (non-vascularised) fibular grafting with recombinant bone morphogenetic protein-7 for the treatment of femoral head osteonecrosis preliminary report. Bone Joint J 96(1):31-35

39. Morko J, Peng Z, Fagerlund K, Konkol Y, Rissanen J, Bernoulli J, Halleen J (2014) Intra-articular treatment with recombinant human bone morphogenetic protein 7 (BMP-7) attenuates the development of osteoarthritis in a surgically induced rat model. Osteoarthr Cartil 22:S465

40. Wang Z, Hutton WC, Yoon ST (2014) Bone morphogenetic protein-7 antagonizes tumor necrosis factor-alpha-induced activation of nuclear factor kappaB and up-regulation of the ADAMTS, leading to decreased degradation of disc matrix macromolecules aggrecan and collagen II. Spine J 14(3):505-512. doi:10.1016/j. spinee.2013.08.016

41. Shen B, Wei A, Whittaker S, Williams LA, Tao H, Ma DDF, Diwan AD (2009) The role of BMP-7 in chondrogenic and osteogenic differentiation of human bone marrow multipotent mesenchymal stromal cells in vitro. J Cell Biochem 109(2):406-416. doi:10. $1002 /$ jcb. 22412

42. Im H-J, Pacione C, Chubinskaya S, van Wijnen AJ, Sun Y, Loeser RF (2003) Inhibitory effects of insulin-like growth factor1 and osteogenic protein- 1 on fibronectin fragment-and interleukin-1 $\beta$-stimulated matrix metalloproteinase-13 expression in human chondrocytes. J Biol Chem 278(28):25386-25394

43. Chen P, Vukicevic S, Sampath TK, Luyten FP (1995) Osteogenic protein-1 promotes growth and maturation of chick sternal chondrocytes in serum-free cultures. J Cell Sci 108(1):105-114

44. Gu K, Zhang L, Jin T, Rutherford RB (2004) Identification of potential modifiers of Runx2/Cbfa 1 activity in $\mathrm{C} 2 \mathrm{C} 12$ cells in response to bone morphogenetic protein-7. Cells Tissues Organs 176(1-3):28-40

45. Sampath TK, Maliakal J, Hauschka P, Jones W, Sasak H, Tucker R, White K, Coughlin J, Tucker M, Pang R (1992) Recombinant human osteogenic protein-1 (hOP-1) induces new bone formation in vivo with a specific activity comparable with natural bovine osteogenic protein and stimulates osteoblast proliferation and differentiation in vitro. J Biol Chem 267(28):20352-20362

46. Chen G, Deng C, Li Y-P (2012) TGF- $\beta$ and BMP signaling in osteoblast differentiation and bone formation. Int J Biol Sci 8(2):272-288. doi:10.7150/ijbs.2929

47. Tsuji K, Cox K, Gamer L, Graf D, Economides A, Rosen V (2009) Conditional deletion of BMP7 from the limb skeleton does not affect bone formation or fracture repair. J Orth Res 28(3):284-289. doi:10.1002/jor.20996

48. Zeisberg M (2006) Bone morphogenic protein-7 and the kidney: current concepts and open questions. Nephrol Dial Transplant 21(3):568-573. doi:10.1093/ndt/gfk010

49. Lund RJ (2004) Successful treatment of an adynamic bone disorder with bone morphogenetic protein-7 in a renal ablation model. J Am Soc Nephrol 15(2):359-369. doi:10.1097/01.asn. 0000109671.99498 .08

50. Mocini D, Leone T, Tubaro M, Santini M, Penco M (2007) Structure, production and function of erythropoietin: implications for therapeutical use in cardiovascular disease. Curr Med Chem 14(21):2278-2287

51. Moore E, Bellomo R (2011) Erythropoietin (EPO) in acute kidney injury. Ann Intensive Care 1(1):1-10

52. Ribatti D, Wan L, Zhang F, He Q, Tsang WP, Lu L, Li Q, Wu Z, Qiu G, Zhou G, Wan C (2014) EPO promotes bone repair through enhanced cartilaginous callus formation and angiogenesis. PLoS One 9(7):e102010. doi:10.1371/journal.pone.0102010

53. Rölfing JHD, Bendtsen M, Jensen J, Stiehler M, Foldager CB, Hellfritzsch MB, Bünger C (2012) Erythropoietin augments bone formation in a rabbit posterolateral spinal fusion model. J Orthop Res 30(7):1083-1088. doi:10.1002/jor.22027

54. Gonçalves R, Shiozawa Y, Jung Y, Ziegler AM, Pedersen EA, Wang J, Wang Z, Song J, Wang J, Lee CH, Sud S, Pienta KJ, Krebsbach PH, Taichman RS (2010) Erythropoietin couples hematopoiesis with bone formation. PLoS One 5(5):e10853. doi:10.1371/journal.pone. 0010853

55. Hiram-Bab S, Liron T, Deshet-Unger N, Mittelman M, Gassmann M, Rauner M, Franke K, Wielockx B, Neumann D, Gabet Y (2015) Erythropoietin directly stimulates osteoclast precursors and induces bone loss. FASEB J 29(5):1890-1900. doi:10.1096/fj.14-259085

56. Rölfing JHD, Baatrup A, Stiehler M, Jensen J, Lysdahl H, Bünger C (2013) The osteogenic effect of erythropoietin on human mesenchymal stromal cells is dose-dependent and involves non- 
hematopoietic receptors and multiple intracellular signaling pathways. Stem Cell Rev Rep 10(1):69-78. doi:10.1007/s12015013-9476-X

57. Baud'huin M, Duplomb L, Teletchea S, Lamoureux F, RuizVelasco C, Maillasson M, Redini F, Heymann M-F, Heymann D (2013) Osteoprotegerin: multiple partners for multiple functions. Cytokine Growth Factor Rev 24(5):401-409. doi:10.1016/j. cytogfr.2013.06.001

58. Kazama JJ, Shigematsu T, Yano K, Tsuda E, Miura M, Iwasaki Y, Kawaguchi Y, Gejyo F, Kurokawa K, Fukagawa M (2002) Increased circulating levels of osteoclastogenesis inhibitory factor (osteoprotegerin) in patients with chronic renal failure. Am J Kidney Dis 39(3):525-532

59. Bargnoux A-S, Dupuy A-M, Garrigue V, Deleuze S, Cristol J, Mourad G (2006) Renal transplantation decreases osteoprotegerin levels. Transplant Proc 38(7):2317-2318

60. Winkler DG, Sutherland MK, Geoghegan JC, Yu C, Hayes T, Skonier JE, Shpektor D, Jonas M, Kovacevich BR, StaehlingHampton K (2003) Osteocyte control of bone formation via sclerostin, a novel BMP antagonist. EMBO J 22(23):6267-6276

61. Li X, Zhang Y, Kang H, Liu W, Liu P, Zhang J, Harris SE, Wu D (2005) Sclerostin binds to LRP5/6 and antagonizes canonical Wnt signaling. J Biol Chem 280(20):19883-19887

62. Sutherland MK, Geoghegan JC, Yu C, Turcott E, Skonier JE, Winkler DG, Latham JA (2004) Sclerostin promotes the apoptosis of human osteoblastic cells: a novel regulation of bone formation. Bone 35(4):828-835. doi:10.1016/j.bone.2004.05.023

63. Thambiah S, Roplekar R, Manghat P, Fogelman I, Fraser W, Goldsmith D, Hampson G (2012) Circulating sclerostin and Dickkopf-1 (DKK1) in predialysis chronic kidney disease (CKD): relationship with bone density and arterial stiffness. Calcif Tissue Int 90(6):473-480

64. Bonani M, Rodriguez D, Fehr T, Mohebbi N, Brockmann J, Blum M, Graf N, Frey D, Wüthrich RP (2014) Sclerostin blood levels before and after kidney transplantation. Kidney Blood Press Res 39(4):230-239. doi:10.1159/000355781

65. Isakova T, Wahl P, Vargas GS, Gutierrez OM, Scialla J, Xie H, Appleby D, Nessel L, Bellovich K, Chen J, Hamm L, Gadegbeku C, Horwitz E, Townsend RR, Anderson CA, Lash JP, Hsu CY, Leonard MB, Wolf M (2011) Fibroblast growth factor 23 is elevated before parathyroid hormone and phosphate in chronic kidney disease. Kidney Int 79(12):1370-1378. doi:10.1038/ki. 2011.47

66. Oliveira RB, Cancela AL, Graciolli FG, Dos Reis LM, Draibe SA, Cuppari L, Carvalho AB, Jorgetti V, Canziani ME, Moyses RM (2010) Early control of PTH and FGF23 in normophosphatemic CKD patients: a new target in CKD-MBD therapy? Clin J Am Soc Nephrol 5(2):286-291. doi:10.2215/CJN.05420709
67. Sun N, Guo Y, Liu W, Densmore M, Shalhoub V, Erben RG, Ye L, Lanske B, Yuan Q (2015) FGF23 neutralization improves bone quality and osseointegration of titanium implants in chronic kidney disease mice. Sci Rep 5:8304. doi:10.1038/srep08304

68. Huang JC, Sakata T, Pfleger LL, Bencsik M, Halloran BP, Bikle DD, Nissenson RA (2004) PTH differentially regulates expression of RANKL and OPG. J Bone Miner Res 19(2):235-244. doi:10.1359/JBMR.0301226

69. Liu Q, Wan Q, Yang R, Zhou H, Li Z (2012) Effects of intermittent versus continuous parathyroid hormone administration on condylar chondrocyte proliferation and differentiation. Biochem Biophys Res Commun 424(1):182-188. doi:10.1016/j.bbrc.2012.06.106

70. Ishizuya $\mathrm{T}$, Yokose $\mathrm{S}$, Hori $\mathrm{M}$, Noda $\mathrm{T}$, Suda $\mathrm{T}$, Yoshiki S, Yamaguchi A (1997) Parathyroid hormone exerts disparate effects on osteoblast differentiation depending on exposure time in rat osteoblastic cells. J Clin Invest 99(12):2961-2970

71. Swarthout JT, D'Alonzo RC, Selvamurugan N, Partridge NC (2002) Parathyroid hormone-dependent signaling pathways regulating genes in bone cells. Gene 282(1):1-17

72. Demay MB, Kiernan MS, DeLuca HF, Kronenberg HM (1992) Sequences in the human parathyroid hormone gene that bind the 1, 25-dihydroxyvitamin D3 receptor and mediate transcriptional repression in response to 1, 25-dihydroxyvitamin D3. Proc Natl Acad Sci 89(17):8097-8101

73. Zierold C, Mings JA, DeLuca HF (2001) Parathyroid hormone regulates 25-hydroxyvitamin $\mathrm{D}(3)$-24-hydroxylase mRNA by altering its stability. Proc Natl Acad Sci USA 98(24):13572-13576

74. de Groot T, Lee K, Langeslag M, Xi Q, Jalink K, Bindels RJ, Hoenderop JG (2009) Parathyroid hormone activates TRPV5 via PKA-dependent phosphorylation. J Am Soc Nephrol 20(8):16931704. doi:10.1681/ASN.2008080873

75. Lavi-Moshayoff V, Wasserman G, Meir T, Silver J, Naveh-Many $\mathrm{T}$ (2010) PTH increases FGF23 gene expression and mediates the high-FGF23 levels of experimental kidney failure: a bone parathyroid feedback loop. Am J Physiol Renal Physiol 299(4):F882-F889. doi:10.1152/ajprenal.00360.2010

76. Ben-Dov IZ, Galitzer H, Lavi-Moshayoff V, Goetz R, Kuro-o M, Mohammadi M, Sirkis R, Naveh-Many T, Silver J (2007) The parathyroid is a target organ for FGF23 in rats. J Clin Invest 117(12):4003-4008. doi:10.1172/JCI32409

77. Olauson H, Lindberg K, Amin R, Sato T, Jia T, Goetz R, Mohammadi M, Andersson G, Lanske B, Larsson TE (2013) Parathyroid-specific deletion of Klotho unravels a novel calcineurin-dependent FGF23 signaling pathway that regulates PTH secretion. PLoS Genet 9(12):e1003975. doi:10.1371/journal. pgen. 1003975 